\title{
Further evidence of endogenous hydrogen sulphide as a mediator of relaxation in human and rat bladder
}

\author{
Jun-Wei Gai ${ }^{1,2, *}$, Wasilijiang Wahafu ${ }^{3, *}$, Hui Guo ${ }^{4}$, Miao Liu ${ }^{5}$, Xu-Chang Wang ${ }^{1,2}$, Yun-Xiang Xiao ${ }^{1,2}$, \\ Liang Zhang ${ }^{6}$, Zhong-Cheng Xin ${ }^{2,7}$ and Jie Jin ${ }^{1,2}$
}

We investigated the expression of hydrogen sulphide $\left(\mathrm{H}_{2} \mathrm{~S}\right)$ in human and rat lower urinary tract (including bladder, prostate and urethra) tissues, and we sought to determine whether $\mathrm{H}_{2} \mathrm{~S}$ induces relaxation of human and Sprague-Dawley (SD) rat bladder strips. Human normal lower urinary tract tissue was obtained for the evaluation of endogenous $\mathrm{H}_{2} \mathrm{~S}$ productivity using a sulphide-sensitive electrode and for the analysis of the expression levels of all three synthases of endogenous $\mathrm{H}_{2} \mathrm{~S}$, cystathionine $\beta$-synthase (CBS), cystathionine $\gamma$ lyase (CSE) and 3-mercaptopyruvate sulphur transferase (MPST, as known as 3-MST) by Western blot assay. CBS, CSE and MPST were located in human sample slides by immunohistochemistry. Human and male adult SD rat bladder strips were tested for $\mathrm{H}_{2} \mathrm{~S}$ function with a transducer and recorded. All experiments were repeated six times. The endogenous $\mathrm{H}_{2} \mathrm{~S}$ productivity and the $\mathrm{H}_{2} \mathrm{~S}$ synthases had various distributions in the human and rat lower urinary tract tissues and were located in both epithelial and stromal sections. L-cysteine ( $L$-Cys, a substrate of CBS, CSE and MPST) elicited relaxation in a dose-dependent manner on human bladder strips pre-contracted by acetylcholine chloride. This effect could be diminished by the ATP-sensitive potassium ion $\left(\mathrm{K}_{\mathrm{ATP}}\right)$ channel blocker glibenclamide (GLB), the CSE inhibitor DL-propargylglycine (PPG) and the CBS inhibitor hydroxylamine (HA). $\mathrm{H}_{2} \mathrm{~S}$ and its three synthases were present in the human and rat lower urinary tract tissues and relaxed human and rat bladder strips, which implied that endogenous $\mathrm{H}_{2} \mathrm{~S}$ might play a role in physiological function and pathological disorders of the lower urinary tract symptoms (LUTS) or overactive bladder (OAB).

Asian Journal of Andrology (2013) 15, 692-696; doi:10.1038/aja.2013.32; published online 3 June 2013

Keywords: cystathionine $\beta$-synthase; cystathionine $\gamma$ lyase; detrusor; hydrogen sulphide; lower urinary tract symptoms; 3-mercaptopyruvate sulphur transferase

\section{INTRODUCTION}

Hydrogen sulphide $\left(\mathrm{H}_{2} \mathrm{~S}\right)$, which is endogenously catalysed by cystathionine $\beta$-synthase (CBS), cystathionine $\gamma$ lyase (CSE) derived from $L$-cysteine ( $L$-Cys) and 3-mercaptopyruvate sulphur transferase (MPST, as known as 3-MST) through one-carbon metabolism and transsulphuration pathway, have been identified as novel non-adrenergic and non-cholinergic signal transmitters. ${ }^{1-3}$ Various mammalian tissues have been proven to produce $\mathrm{H}_{2} \mathrm{~S}$. Endogenous $\mathrm{H}_{2} \mathrm{~S}$ can relax mammalian cardiovascular, corpus cavernosum, vas deferens smooth muscle and human bladder. ${ }^{4-7}$ Bucci et al. ${ }^{8}$ even noted that $\mathrm{H}_{2} \mathrm{~S}$ was involved in testosterone vascular effects, which made $\mathrm{H}_{2} \mathrm{~S}$ more attractive for urological researchers. Our previous study had also revealed the expression and characterisation of $\mathrm{H}_{2} \mathrm{~S}$ in human prostatic tissue and cell lines. ${ }^{9}$ Although Fusco et al. ${ }^{10}$ demonstrated the generation and function of endogenous $\mathrm{H}_{2} \mathrm{~S}$ and its synthases in human bladder tissue, they did not analyse the expression of MPST in human bladder tissue and the function of $\mathrm{H}_{2} \mathrm{~S}$ on rat bladder tissue, whereas the latter remains controversial.
Dysfunctional lower urinary smooth muscle, such as bladder detrusor contraction and relaxation, is of great importance in lower urinary tract symptoms (LUTS), often resulting from damaged bladder detrusor function in aged men. ${ }^{11}$ Alleviating detrusor function remains difficult for urologists. ${ }^{12,13}$ Usually patients with LUTS are treated with $\alpha$-adrenergic blockers or anti-cholinergic drugs to control undesired urinary smooth muscle contraction, ${ }^{14,15}$ whereas newly emerging mechanisms or hypotheses provide urological researchers with alternative therapeutic options. ${ }^{16}$

In this present study, we analysed the endogenous $\mathrm{H}_{2} \mathrm{~S}$ productivity and expression levels of CBS, CSE and MPST in human and rat bladder, prostate and urethra tissue, respectively, and explored the effects of $\mathrm{H}_{2} \mathrm{~S}$ on the tone of bladder strips from humans and Sprague-Dawley (SD) rats.

\section{MATERIALS AND METHODS}

Tissue samples and animals

Informed consent and samples were obtained from 56 patients with bladder cancer (mean age: 64.3 years, age range: $54-76$ years) who had

${ }^{1}$ Department of Urology, Peking University First Hospital, Beijing 100034, China; ${ }^{2}$ The Institute of Urology, Peking University, Beijing 100034 , China; ${ }^{3}$ Department of Urology, PLA General Hospital, Beijing 100853, China; ${ }^{4}$ Department of Urology, Tsinghua University First Hospital, Beijing 100016, China; ${ }^{5}$ Hedong Center for Disease Control and Prevention, Tianjin 300151, China; ${ }^{6}$ Department of Orthopaedic Surgery, Beijing Jishuitan Hospital, Fourth Clinical College of Peking University, Beijing 100035, China and ${ }^{7}$ Andrology Center, Peking University First Hospital, Beijing 100034, China

* These authors contributed equally to this work.

Correspondence: Professor ZC Xin (xinzc@bjmu.edu.cn) and Professor J Jin (Jinjie@vip.163.com)

Received: 18 November 2012; Revised: 20 December 2012; Accepted: 14 March 2013; Published online: 3 June 2013 
undergone radical cystoprostatectomy in Peking University First Hospital from October 2009 to December 2011. Bladder tissue samples were removed and confirmed to be cancer-free by experienced urological pathologists. Adult male SD rats (8 months old) weighing 350-450 g were purchased from the Experimental Animal Center of Peking University Health Science. This study was approved by the Institutional Research Ethical Board. Freshly removed human and rat tissues were both fixed in paraformaldehyde solution for $24 \mathrm{~h}$ and then paraffin-embedded for immunohistochemistry or frozen immediately and stored in liquid nitrogen. Human bladder strips were prepared according to a published article. ${ }^{10}$

\section{Immunohistochemistry}

The expression and location of CBS, CSE and MPST in the human bladder, prostate and urethra tissues were examined by immunohistochemistry. Tissue samples were formalin-fixed for $24 \mathrm{~h}$ and then paraffin-embedded. Slides of $5 \mu \mathrm{m}$ thickness were prepared and dewaxed. After the antigens were retrieved, the slides were treated with $3 \%$ hydrogen peroxide for $15 \mathrm{~min}$ and incubated with normal goat serum for $30 \mathrm{~min}$ to block nonspecific-binding sites. The slides were incubated with primary antibody against CBS (Abnova, Taiwan, China), CSE (Abnova) and MPST (Santa Cruz Biotechnology, Santa Cruz, CA, USA) at $1: 100$ overnight at $4{ }^{\circ} \mathrm{C}$. The slides were then washed with phosphate-buffered saline containing $0.1 \% \mathrm{v} / \mathrm{v}$ Tween20 and incubated with horseradish peroxidase-conjugated goat antimouse immunoglobulin (Santa Cruz Biotechnology) for $20 \mathrm{~min}$ at room temperature. Finally, the slides were treated with peroxidaseconjugated streptavidin and stained with DAB. The results were photographed by optical microscope (Olympus, Tokyo, Japan).

\section{Western blot semiquantity assay}

Human and rat tissue samples were prepared in RIPA buffer with protease and phosphatase inhibitors (BD Pharmingen, San Diego, CA, USA). Protein samples $(50 \mu \mathrm{g})$ were separated in $10 \%$ sodium dodecyl sulphate-polyacrylamide gels (Sigma-Aldrich, St Louis, $\mathrm{MO}$, USA) and transferred to a nitrocellulose membrane (BD Pharmingen). The membranes were blocked with non-fat milk in Tris-Buffered Saline with Tween (BD Pharmingen) and probed with primary antibodies against CBS or CSE at $1: 1000$ and against MPST at 1:500, followed by secondary goat anti-mouse IgG antibodies (Santa Cruz Biotechnology). The signals were developed by ECL reagent (GE Healthcare Bioscience, Piscataway, NJ, USA) and then recorded. The results were semi-quantifiably assayed by a KODAK Image Station (Kodak, Rochester, NY, USA).

\section{Endogenous $\mathrm{H}_{2} \mathrm{~S}$ productivity measurements}

The measurements of the $\mathrm{H}_{2} \mathrm{~S}$ contents were performed as previously mentioned. ${ }^{17}$ The tissue samples were homogenised in a 10-fold volume $(\mathrm{w} / \mathrm{v})$ of an ice-cold potassium phosphate buffer $(\mathrm{pH}=6.8)$. The reaction was performed in a 25-ml Erlenmeyer Pyrex flask, and within the flask, there was a specially made glass chamber (diameter $1 \mathrm{~cm}$ and height $2 \mathrm{~cm}$ ). Cryovial test tubes $(2 \mathrm{ml})$ were used as the centre wells, each containing $0.5 \mathrm{ml}$ of $1 \mathrm{~mol}^{-1} \mathrm{NaOH}$. The sulphursensitive electrode (PXS-270, Shanghai, China) was used to evaluate the endogenous $\mathrm{H}_{2} \mathrm{~S}$ productivity. A preparation of $500 \mu \mathrm{l}$ of tissue homogenate mixed with $500 \mu \mathrm{l}$ of pre-cooled $50 \mathrm{mmol} \mathrm{l}^{-1} \mathrm{pH} 6.8$ phosphate-buffered saline and $1 \mathrm{ml}$ of reacting system solution (100 mmol $~^{-1} \mathrm{pH} 7.4$ phosphate-buffered saline, $10 \mathrm{mmol} \mathrm{l}^{-1}$ $L$-Cys (Sigma-Aldrich), $2 \mathrm{mmol}^{-1}$ phosphate pyridoxine aldehyde) was made. Then, $2 \mathrm{ml}$ of the mixed solution was moved to the flask outer room after the sample protein concentration was determined, and $1 \mathrm{ml}$ of $1 \mathrm{~mol} \mathrm{l}^{-1} \mathrm{NaOH}$ was added to the central room of the bottle. The sealed flask was incubated at $37^{\circ} \mathrm{C}$ water bath for $90 \mathrm{~min}$, and then $1 \mathrm{ml}$ of $50 \%$ trichloroacetic acid was added to end the reaction. The incubation of the whole flask was continued at $37^{\circ} \mathrm{C}$ for $60 \mathrm{~min}$. The contents were transferred from the central wells to the corresponding wells of a 12-well cell culture cluster (Corning, Corning, NY, USA), each containing $1 \mathrm{ml}$ of the antioxidant solution. Subsequently, the solution was measured with the sulphide-sensitive electrode to calculate the $\mathrm{H}_{2} \mathrm{~S}$ contents against a standard curve. After adjusting with the protein concentration in the corresponding samples, the endogenous $\mathrm{H}_{2} \mathrm{~S}$ productivity was expressed in $\mathrm{nmol} \mathrm{min}^{-1} \mathrm{mg}^{-1}$ and calculated as the mean \pm s.d.

\section{Organ bath experiments}

Human bladder samples from donor patients or SD rat bladder strips were immediately placed in oxygenated $4{ }^{\circ} \mathrm{C}$ Krebs solution. Each human or rat bladder prepared tissue was a longitudinal strip of approximately $2 \mathrm{~mm} \times 10 \mathrm{~mm}$ and randomly divided into different treated groups.

The strips were transferred to a $25 \mathrm{ml}$ organ bath container, filled with oxygenated Krebs solution at $37.0{ }^{\circ} \mathrm{C}$, and connected to force transducers. After $40 \mathrm{~min}$ of equilibration, the initial tension of strips was adjusted to precisely $1 \mathrm{~g}$. The strips were then pre-contracted with $20 \mathrm{mmol} \mathrm{l}^{-1}$ acetylcholine chloride (Sigma-Aldrich) in Krebs solution. When the contraction reached its peak and was stabilised, the experiments were performed. The relaxation degrees were expressed as the percentage of the initial tension.

\section{Statistical analysis}

The values are represented as the means \pm s.d. and were analysed using LSD post hoc test by SPSS 17.0 software. $P<0.05$ was considered statistically significant.

\section{RESULTS}

\section{CBS, CSE and MPST expression in human bladder, prostate and} urethra tissues

Human sections of smooth muscle layer presented higher expression levels of CSE, compared with those of CBS and MPST (Figure 1), which were confirmed by Western blot (Figure 2a). The SD rat tissue presented different expression patterns of CBS, CSE and MPST (Figure 2b) by Western blot assay.

\section{$\mathrm{H}_{2} \mathrm{~S}$ productivity in human and rat bladder, prostate and urethra tissues}

The $\mathrm{H}_{2} \mathrm{~S}$ productivities of human bladder, prostate, and urethra were

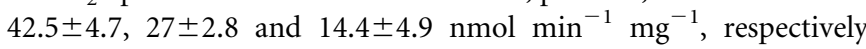
(Figure 2c). The $\mathrm{H}_{2} \mathrm{~S}$ productivities of SD rat bladder, prostate, and urethra were $143.3 \pm 12.2,50 \pm 4.7$ and $117.1 \pm 15.7 \mathrm{nmol} \mathrm{min}^{-1} \mathrm{mg}^{-1}$, respectively (Figure 2d).

$\mathrm{H}_{2} \mathrm{~S}$-induced relaxation on human and SD rat bladder strips was blocked by glibenclamide (GLB), DL-propargylglycine (PPG) and hydroxylamine (HA)

$\mathrm{NaHS}$ (the exogenous $\mathrm{H}_{2} \mathrm{~S}$ donor; Sigma-Aldrich) and $L$-Cys (the endogenous substrate of the $\mathrm{H}_{2} \mathrm{~S}$ synthases; Sigma-Aldrich) plus $10^{-6} \mathrm{~mol} \mathrm{l}^{-1} 5^{\prime}$-pyridoxal phosphate as the coenzyme all relaxed the bladder strips in a dose-dependent manner. This effect could be diminished by GLB (a KATP channel inhibitor; Sigma-Aldrich), PPG (a specific CSE inhibitor; Sigma-Aldrich) and HA (a specific 


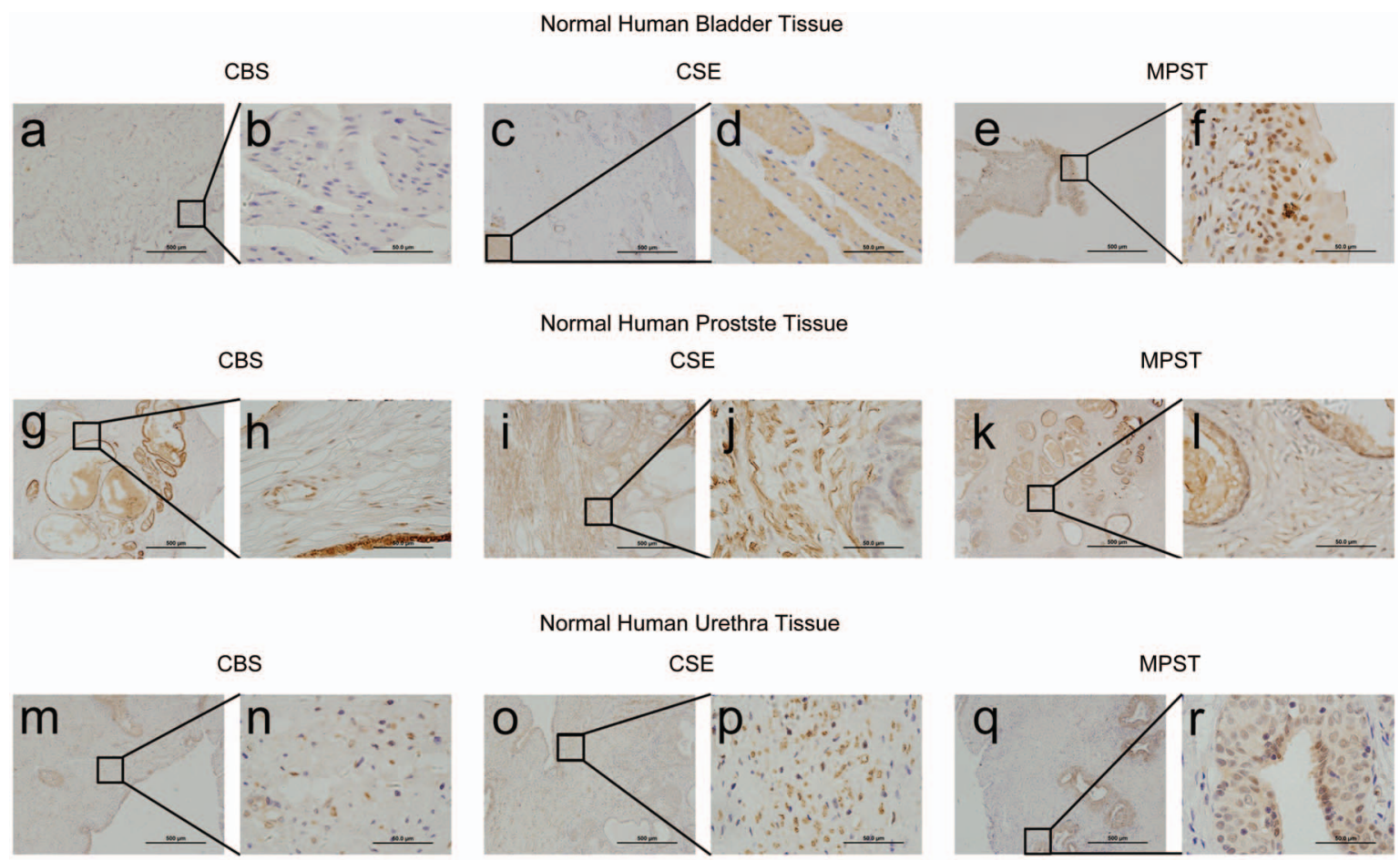

Figure 1 Immunohistochemical staining, protein levels and $\mathrm{H}_{2} \mathrm{~S}$ productivities of CBS, CSE and MPST in cancer-free human bladder, prostate and urethra tissues. The urothelial cell layers showed little or no staining of CBS, CSE, and MPST, whereas the bladder muscular layer showed high signals of CSE and MPST. CBS, cystathionine $\beta$-synthase; CSE, cystathionine $\gamma$ lyas; MPST, 3-mercaptopyruvate sulphur transferase. For a, c, e, g, i, k, m, o and q, scale bar=500 $\mu$ m. For b, d, f, h, j, l, $\mathrm{n}, \mathrm{p}$ and $\mathrm{r}$, scale bar $=50 \mu \mathrm{m}$.

CBS inhibitor; Sigma-Aldrich) (Figure 3). The strips were pre-contracted with $20 \mathrm{mmol} \mathrm{l}^{-1}$ Ach in Krebs solution and then incubated with different doses of GLB $\left(25-75 \mu \mathrm{mol}^{-1}\right)$ before the NaHS-induced relaxation. In addition, the strips were incubated with different doses of PPG (25-75 $\left.\mu \mathrm{mol} \mathrm{l}^{-1}\right)$ or different doses of HA $\left(25-75 \mu \mathrm{mol} \mathrm{l}{ }^{-1}\right)$ before the $L$-Cys-induced relaxation. GLB, $50 \mu \mathrm{moll}^{-1}$ and $75 \mu \mathrm{mol} \mathrm{l}^{-1}$, a

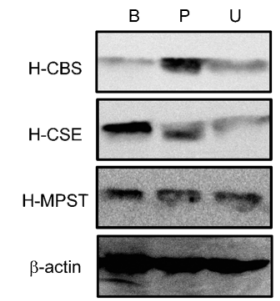

C

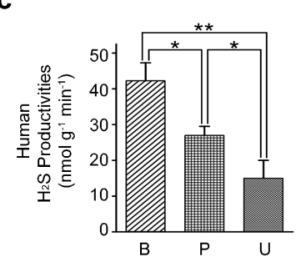

b

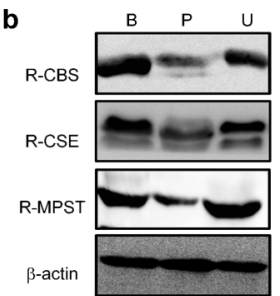

d

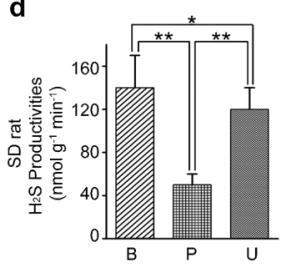

Figure 2 Protein expression levels of CBS, CSE and MPST varied in normal human and SD rat bladder, prostate and urethra tissues ( $\mathbf{a}$ and $\mathbf{b}$ ), which was confirmed by the $\mathrm{H}_{2} \mathrm{~S}$ productivity analysis (c and $\mathbf{d}$ ). The relative protein expression levels were calculated by normalisation to the GAPDH expression level. The $\mathrm{H}_{2} \mathrm{~S}$ productivity results are expressed as the means \pm s.d. ( $* P<0.05$ and $* * P<0.01)$. CBS, cystathionine $\beta$-synthase; CSE, cystathionine $\gamma$ lyas; MPST, 3-mercaptopyruvate sulphur transferase. attenuated the NaHS $\left(10^{-3} \mathrm{~mol} \mathrm{l}^{-1}\right)$ relaxation effects on the human and SD rat bladder strips significantly $(P=0.0165, P=0.0061, P=0.0089$ and $P=0.0066$, respectively) (Figure $3 \mathrm{a}$ and $3 d$ ). PPG at $75 \mu \mathrm{mol} 1^{-1}$ attenuated the $L$-Cys $\left(10^{-3} \mathrm{~mol} \mathrm{l}^{-1}\right)$ relaxation on the human and SD rat bladder strips significantly ( $P=0.0315$ and $P=0.0403$, respectively) (Figure $3 \mathbf{b}$ and $3 \mathbf{e}$ ), but HA decreased the relaxation effect of $L$-Cys on the strips in both species (Figure $3 \mathrm{c}$ and $\mathbf{3 f}$ ).

\section{DISCUSSION}

Recent studies showed that $\mathrm{H}_{2} \mathrm{~S}$ and its synthases CBS and CSE existed in human bladder tissue and contributed to the relaxing effect of sildenafil on the human dome of the detrusor, which was independent of the traditional adrenergic and cholinergic receptor to some extent. ${ }^{10,16,18,19}$ Given that dysfunction of the bladder detrusor partially contributes to LUTS, confirming and further exploring the expression and function of this newly gaseous signal in urination might be worthwhile. Our study demonstrated that not only CBS and CSE but also MPST were present in human and rat bladder tissue. Moreover, there were different expression patterns of $\mathrm{H}_{2} \mathrm{~S}$ and its synthases in the bladder, prostate, and urethra tissues between human and SD rat. In the present study, we observed that exogenous and endogenous $\mathrm{H}_{2} \mathrm{~S}$ could relax acetylcholine chloride-induced bladder strips.

Previous studies showed that exogenous $\mathrm{H}_{2} \mathrm{~S}$ could elicit various responses in rat and trout bladder with different pre-treatments. ${ }^{20-22}$ We observed in the midst of $\mathrm{H}_{2} \mathrm{~S}$, the relaxation of smooth muscle precontracted with acetylcholine chloride. Streng et al. ${ }^{20}$ investigated the transient receptor potential vanilloid receptor 1 and showed that it might be involved in the contraction induced by NaHS when rat bladder strips were electrically stimulated. Patacchini et al. ${ }^{21}$ reported 

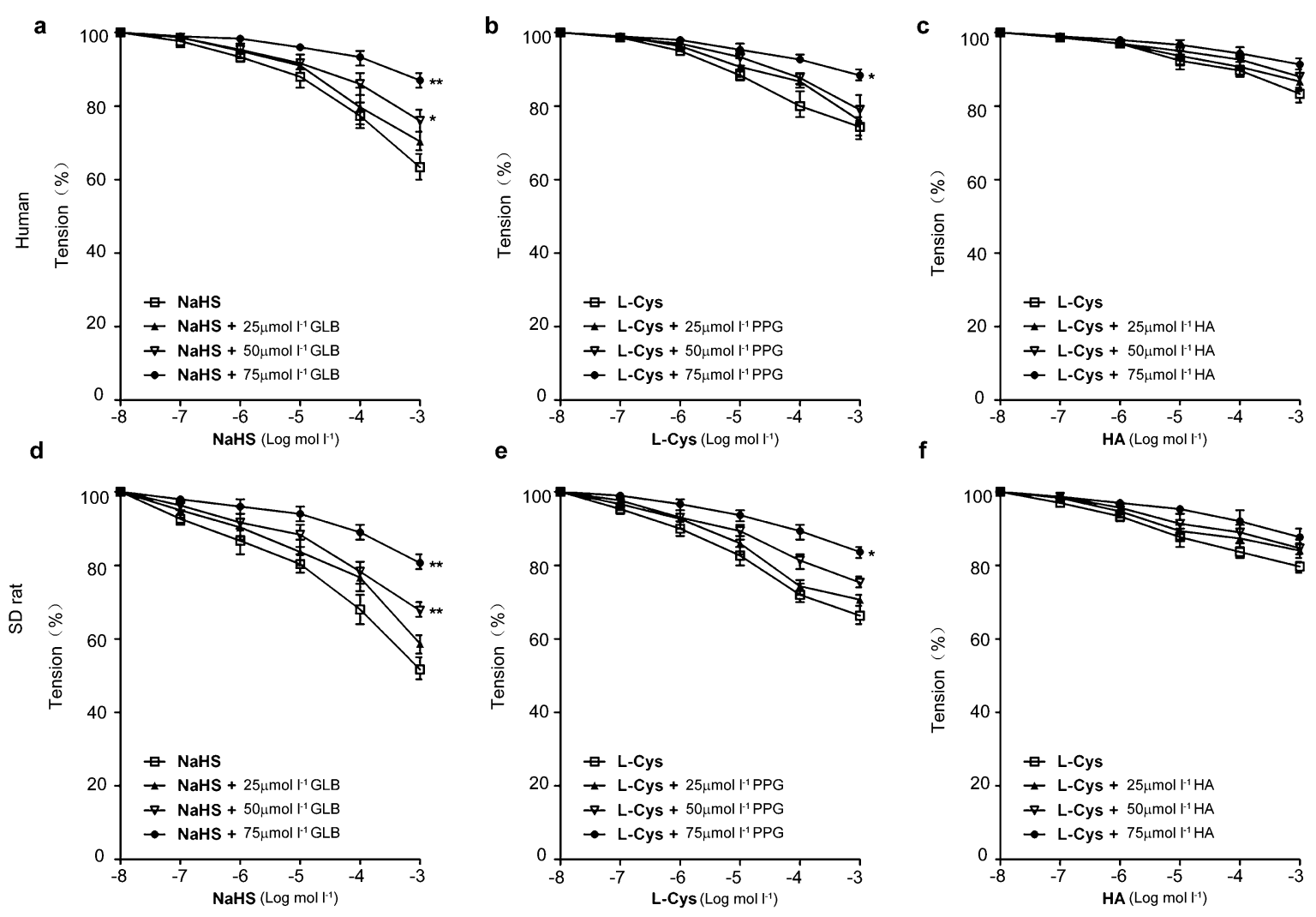

Figure $3 \mathrm{H}_{2} \mathrm{~S}$-induced relaxation on human and SD rat bladder strips was blocked by GLB, PPG and HA, as shown in NaHS-relaxed human (a) and rat (d) bladder strips, in a dose-dependent manner. PPG attenuated the L-Cys-induced relaxation of strips of human (b) and rat (e) bladder in a dose-dependent manner. HA diminished $L$-Cys-induced relaxation of strips of human (c) and rat bladder in a dose-dependent manner (f). All data are expressed as the means \pm s.d. $(* P<0.05$ and ** $P<0.01)$. GLB, glibenclamide; HA, hydroxylamine; L-Cys, L-cysteine; PPG, DL-propargylglycine; SD, Sprague-Dawley.

that intravesical NaHS instillation increased protamine sulphate pretreated rat bladder pressure. Dombkowski et al. ${ }^{22}$ explored the $\mathrm{H}_{2} \mathrm{~S}$ effects on trout bladder smooth muscle and suggested that $\mathrm{H}_{2} \mathrm{~S}$ could produce a dose-dependent relaxation in unstimulated and carbachol pre-contracted bladders and inhibit spontaneous contractions. $\mathrm{KCl}$, adrenergic and cholinergic agonists would usually be chosen to precontract smooth muscle in not only LUT but also cardiovascular vessels, gastrointestinal tract, and corpus cavernosum tissues. ${ }^{2,5,6,7,23,24}$ Taken together, we proposed that the effect of $\mathrm{H}_{2} \mathrm{~S}$ on human and rat bladder smooth muscle tone might play various roles, depending on different pretreatments. ${ }^{20,21}$ In our study, exogenous and endogenous $\mathrm{H}_{2} \mathrm{~S}$ relaxed smooth muscle that was pre-contracted with acetylcholine chloride. This effect was diminished by GLB, PPG and HA. HA is a specific CBS inhibitor that blocks the biosynthesis of $\mathrm{H}_{2} \mathrm{~S}$ de novo prior to CSE and MPST, ${ }^{25}$ which might explain why HA produces a strong effect on restraining the endogenous biosynthesis of $\mathrm{H}_{2} \mathrm{~S}$.

$\mathrm{H}_{2} \mathrm{~S}$ has been reported to be an endogenous activator targeting $\mathrm{K}_{\mathrm{ATP}}$ channels and relaxing vascular smooth muscle mainly via opening the $\mathrm{K}_{\mathrm{ATP}}$ channels on the membrane of muscular cell, whereas this effect could be attenuated by the $\mathrm{K}_{\mathrm{ATP}}$ channel blocker GLB. ${ }^{19}$ Although endogenous $\mathrm{H}_{2} \mathrm{~S}$ and its synthases have only been studied in human bladder tissue, $\mathrm{K}_{\mathrm{ATP}}$ channels have been postulated to affect detrusor function since the 1980s. ${ }^{10,26}$ Numerous studies showed that there are different $\mathrm{K}_{\mathrm{ATP}}$ channels present in the human bladder muscular layers. ${ }^{27}$ Our study further proved the expression and function of $\mathrm{H}_{2} \mathrm{~S}$ and its synthases CBS, CSE and MPST in human and rat bladder, prostate and urethra, which reinforced and complemented the study of Fusco et al. ${ }^{10}$ Although the expression and function of $\mathrm{H}_{2} \mathrm{~S}$ in human LUT tissue have been studied widely, the development of new drugs based on $\mathrm{H}_{2} \mathrm{~S}$ or its synthases for the treatment of dysfunctional detrusor remains a challenge.

In summary, we demonstrated that endogenous $\mathrm{H}_{2} \mathrm{~S}$ and its synthases CBS, CSE and MPST are present in human and rat LUT tissue and that it modulated the tone of human and rat bladder strips. Our results indicated that $\mathrm{H}_{2} \mathrm{~S}$ and its synthases may be a newer therapeutic target to treat LUTS induced by undesired bladder contractions, such as OAB.

\section{AUTHOR CONTRIBUTIONS}

JWG participated in the design of the study, carried out the studies and drafted the manuscript. WW, HG, ML, XCW and LZ carried out the studies. YXX, ZCX and JJ participated in the design of the study. All authors read and approved the final manuscript.

\section{COMPETING FINANCIAL INTERESTS}

The authors declare no competing financial interests.

\section{ACKNOWLEDGMENTS}

We thank Professor Jun-Bao Du for providing experimental suggestions and advice, and our study was supported by the National Natural Science Foundation of China (No. 30571851 to Jie Jin, No. 81201527 to Hui Guo).

1 Gadalla MM, Snyder SH. Hydrogen sulfide as a gasotransmitter. J Neurochem 2010; 113: 14-26. 
neg

Expression and function of hydrogen sulphide in human and rat bladder

JW Gar et al

696

2 Tang C, Li X, Du J. Hydrogen sulfide as a new endogenous gaseous transmitter in the cardiovascular system. Cir Vase Pharmacol 2006; 4: 17-22.

3 Wilinski B, Wilinski J, Somogyi E, Piotrowska J, Goralska M. Atorvastatin affects the tissue concentration of hydrogen sulfide in mouse kidneys and other organs. Pharmacol Rep 2011; 63: 184-8.

4 Yang G, Wu L, Jiang B, Yang W, Qi J et al. $\mathrm{H}_{2} \mathrm{~S}$ as a physiologic vasorelaxant: hypertension in mice with deletion of cystathionine gamma-lyase. Science 2008; 322: 587-90.

5 Chang WS, Wong WT, She B, Law CW, Than XY et al. 4-aminopyridine-sensitive $\mathrm{K}^{+}$ channels contributes to NaHS-induced membrane hyperpolarization and relaxation in the rat coronary artery. Vascul Pharmacol 2010; 53: 94-8.

6 d'Emmanuele di Villa Bianca R, Sorrentino R, Maffia P, Mirone V, Imbimbo C et al. Hydrogen sulfide as a mediator of human corpus cavernosum smooth-muscle relaxation. Proc Natl Acid Sci USA 2009; 106: 4513-8.

7 Li J, Li Y, Du Y, Mow K, Sun H et al. Endogenous hydrogen sulfide as a mediator of vas deferens smooth muscle relaxation. Fertil Steril 2011; 95: 1833-85.

8 Bucci M, Mirone V, Di LA, Vellecco V, Roviezzo F et al. Hydrogen sulphide is involved in testosterone vascular effect. Eur Ural 2009; 56: 378-83.

9 Gus H, Gail JW, Wang Y, Hong FJ, Du JB et al. Characterization of hydrogen sulfide and its syntheses, cystathionine $\beta$-synthase and cystathionine $\gamma$-lyse, in human prostatic tissue and cells. Urology 2012; 79: 483.e1-5.

10 Fusco F, d'Emmanuele di Villa Bianca R, Mitidieri E, Cirino G, Sorrentino R et al. Sildenafil effect on the human bladder involves the L-cysteine/hydrogen sulfide pathway: a novel mechanism of action of phosphodiesterase type 5 inhibitors. Eur Ural 2012; 62: 1174-80.

11 Athanasopoulos A, Chapple C, Fowler C, Gratzke C, Kaplan S et al. The role of antimuscarinics in the management of men with symptoms of overactive bladder associated with concomitant bladder outlet obstruction: an update. Eur Ural 2011; 60: 94-105.

12 Mirone V, Imbimbo C, Longe N, Fusco F. The detrusor muscle: an innocent victim of bladder outlet obstruction. Eur Ural 2007; 51: 57-66.

13 Roehrborn CG. Male lower urinary tract symptoms (LUTS) and benign prostatic hyperplasia (BPH). Med Clin North Am 2011; 95: 87-100.

14 Hefner K, Burkart M, Jacob G, Jonas U. Symptomatic and quality of life response to tolterodine in subgroups of men with overactive bladder symptoms and presumed nonobstructive benign prostatic hyperplasia. World J Ural 2010; 28: 353-7.
15 Leper H, Hill LA. Silodosin for the treatment of benign prostatic hyperplasia: pharmacology and cardiovascular tolerability. Pharmacotherapy 2010; 30: 1303-12.

16 Roehrborn CG. Drug treatment for LUTS and BPH: new is not always better. Eur Urol 2006; 49: 5-7.

17 Li X, Jim H, Bin G, Wang L, Tang C et al. Endogenous hydrogen sulfide regulates pulmonary artery collagen remodeling in rats with high pulmonary blood flow. Exp Biol Med (Maywood) 2009; 234: 504-12.

18 Toque HA, Antunes E, Teixeira CE, de Nucci G. Increased cyclic guanosine monophosphate synthesis and calcium entry blockade account for the relaxant activity of the nitric oxide-independent soluble guanylyl cyclase stimulator BAY 41 2272 in the rabbit penile urethra. Urology 2008; 72: 711-5.

19 Zhao W, Zhang J, Lu Y, Wang R. The vasorelaxant effect of $\mathrm{H}_{2} \mathrm{~S}$ as a novel endogenous gaseous $\mathrm{K}_{\mathrm{ATP}}$ channel opener. EMBO J 2001; 20: 6008-16.

20 Strong T, Axelsson HE, Hedlund P, Anderson DA, Jordt SE et al. Distribution and function of the hydrogen sulfide-sensitive TRPA1 ion channel in rat urinary bladder. Eur Ural 2008; 53: 391-9.

21 Patacchini R, Santicioli P, Giuliani S, Magi CA. Pharmacological investigation of hydrogen sulfide $\left(\mathrm{H}_{2} \mathrm{~S}\right)$ contractile activity in rat detrusor muscle. Eur J Pharmacol 2005; 509: 171-7.

22 Dombkowski RA, Doellman MM, Head SK, Olson KR. Hydrogen sulfide mediates hypoxia-induced relaxation of trout urinary bladder smooth muscle. J Exp Biol 2006; 209: 3234-40.

23 Bu FR, Monica FZ, Privier FB, Baldissera L Jr, de Nucci G et al. Evaluation of the relaxant effect of the nitric oxide-independent soluble guanylyl cyclase stimulator BAY 41-2272 in isolated detrusor smooth muscle. Eur J Pharmacol 2010; 637: 171-7.

24 Kodama Y, lino S, Shigemasa Y, Suzuki H. Properties of acetylcholine-induced relaxation of smooth muscle isolated from the proximal colon of the guinea-pig. J Smooth Muscle Res 2010; 46: 185-200.

25 Kimura H. Hydrogen sulfide: its production, release and functions. Amino Acids 2011; 41: 113-21.

26 Gopalakrishnan M, Shieh CC. Potassium channel subtypes as molecular targets for overactive bladder and other urological disorders. Expert Open Then Targets 2004; 8: 437-58.

27 Brading AF. Spontaneous activity of lower urinary tract smooth muscles: correlation between ion channels and tissue function. J Physio 2006; 570: 13-22.

Asian Journal of Andrology 